\title{
THE CATALYTIC PERFORMANCE OF Mg-Al CATALYST IN TRANSESTERIFICATION OF GLYCEROL WITH ETHYLENE CARBONATE
}

\author{
NOOR AZEERAH ABAS*; NIK SITI MARIAM NEK MAT DIN*; HALIZA ABDUL AZIZ*; \\ ZULINA ABD MAURAD* and ZAINAB IDRIS*
}

\begin{abstract}
The development of heterogeneous catalysts for oleochemical reactions is becoming very important, because such catalysts possess well defined catalytic active sites, which will increase catalytic activity and process efficiency. The use of hydrotalcites as heterogeneous catalyst has shown potentials in transesterification reaction due to their physico-chemical properties, such as good thermalstability, good mesoporous material, bigger surface area, good memory effect, and even balanced basicity/acidity active points. The catalytic performance of the calcined Mg-Al catalyst in the green process was developed for the conversion of glycerol to glyceryl carbonate using ethylene carbonate. The X-ray diffraction confirmed the calcined materials exhibit hydrotalcite pattern structure with surface area of $179 \mathrm{~m}^{2} \mathrm{~g}^{-1}$. The HT3.0c comprised of Mg:Al composition of 3:1 was the best catalyst. The catalyst is robust and reusable.
\end{abstract}

Keywords: calcined hydrotalcites, co-precipitation, green chemistry, transesterification, glycerol.

Date received: 29 January 2016; Sent for revision: 6 February 2016; Received in final form: 10 May 2016; Accepted: 11 July 2016.

\section{INTRODUCTION}

Biodiesel has been successfully evaluated as a diesel substitute and has gained worldwide acceptance (Choo et al., 2005). However, every production of biodiesel will produce $10 \% \mathrm{w} / \mathrm{w}$ glycerol as coproduct which needs to be utilised in order to make economics favourable (Fan et al., 2010). It was reported that $66.2 \%$ of the total glycerol was produced from biodiesel industry in 2011. Biodiesel consumption in US rose from 995.56 litres (263 million gallons) in 2010 to 3323.58 litres (878 million gallons) in 2011 to 1 billion litres in 2012. All these production came from 112 biodiesel plants with capacity of 2.2 billion gallons annually (Sonnati et al., 2013).

Malaysian Palm Oil Board, 6 Persiaran Institusi, Bandar Baru Bangi, 43000 Kajang, Selangor, Malaysia.

E-mail: noorazeerah.abas@mpob.gov.my
Therefore, making profit from glycerol, a byproduct from the biodiesel production will be an important way forward to solve the economic and environmental challenges of biofuels production (Choo et al., 2005). There are various field of glycerol applications such as in cosmetic, pharmaceutical and food industries. Oxidation (Prati et al., 2009), etherification (Ruppert et al., 2008), esterification and transesterification (Corma et al., 2005) are examples of chemical processes involving glycerol for the production of value-added products and intermediates.

One important glycerol derivative is glyceryl carbonate (GC) which is widely used as a protic solvent in resins and plastics, a chemical intermediate in organic synthesis and it can also be used as an additive (Murase, 1987). It is a green substitute for important petro-derivative compounds (Shieh et al., 2002; Behr et al., 2008). Glyceryl carbonate is useful in the synthesis of polymers such as polyesters, polycarbonates, polyurethanes, polyamides, 
surfactants and lubricating oils (Yoo et al., 2001). GC offers several advantages. They are less toxic, less flammable, excellent biodegradability and high boiling point (Climent et al., 2010).

Conventionally, preparation of GC is based on the reaction of glycerol with urea, or with carbon monoxide and oxygen (Bell et al., 1959). Another method for the synthesis of GC described in the literature is via transesterification of propylene carbonate with glycerol (Aresta et al., 2009). Mouloungui et al. (1996) patented a process for the manufacture of GC by reacting glycerol with propylene carbonate in the presence of solvent and using zeolites as catalyst. Studies by Sugita et al. (1994) reported that the synthesis of GC using aluminum oxide $\left(\mathrm{Al}_{2} \mathrm{O}_{3}\right)$ as catalyst was conducted under reduced pressure and mild temperature around $140^{\circ} \mathrm{C}$. Wheres Vieville et al. (1998) used zeolite catalyst at $80^{\circ} \mathrm{C}$ with two molar ratio of ethylene carbonate to glycerol to give the desired GC. In this article, characterisation of calcined heterogeneous catalysts and their catalytic activities in the transesterification of glycerol with ethylene carbonate are described.

\section{MATERIALS AND METHODS}

\section{Materials and Catalyst Preparation}

Glycerol $(\geq 99 \%)$, ethylene carbonate $(\geq 99 \%)$, sodium hydroxide $(\geq 99 \%)$ and sodium carbonate $(\geq 99 \%)$ were purchased from Merck. Precursor salts $\mathrm{Mg}\left(\mathrm{NO}_{3}\right)_{2} \cdot 6 \mathrm{H}_{2} \mathrm{O}(\geq 98 \%)$ and $\mathrm{Al}\left(\mathrm{NO}_{3}\right)_{3} \cdot 9 \mathrm{H}_{2} \mathrm{O}$ $(\geq 98 \%)$ were purchased from Bendosen Laboratory Chemicals and used as received. The hydrotalcite catalyst was prepared by adopting the well-known co-precipitation method in a single container of two diluted solutions A and B. Solution A contained divalent cation (288 g) and trivalent cation (140 g) dissolved in 1 litre deionised water.

Solution B acting as precipitating reagent was prepared by dissolving $\mathrm{Na}_{2} \mathrm{CO}_{3}(40 \mathrm{~g})$ and $\mathrm{NaOH}$ (15 g) in 0.5 litres deionised water. The prepared solutions $\mathrm{A}$ and $\mathrm{B}$ were then mixed with a high supersaturation technique for $18 \mathrm{hr}$ at $80^{\circ} \mathrm{C}$ under vigorous stirring. Precipitation occurred and the precipitate was later filtered, washed with hot deionised water until $\mathrm{pH} 7$ and dried overnight at $120^{\circ} \mathrm{C}$. The fresh catalyst obtained, denoted as HT3.0f, was then calcined by heating to $500^{\circ} \mathrm{C}$ in an oven at ramping rate $5^{\circ} \mathrm{C} \mathrm{min}^{-1}$ for $5 \mathrm{hr}$ under nitrogen. The calcined HT3.0f is denoted as HT3.0c.

\section{Catalyst Characterisation}

The synthesised hydrotalcite-type compound HT3.0f and HT3.0c were analysed by X-ray diffraction (XRD) using Bruker D8 ADVANCE diffractometer with a secondary monochromator (Model: Bruker D8 ADVANCE, Germany), using $\mathrm{Cu} \mathrm{K} \alpha 1$ radiation and interface to a DACO-MP data aquisition microprocessor provided with Diffract/ AT software, 2006.

Nitrogen adsorption/desorption isotherms were performed in Micromeritics apparatus (Model: ASAP 2010, USA) after pre-treating the samples under vacuum at $400^{\circ} \mathrm{C}$ overnight and surface areas were obtained through the BrunauerEmmett-Teller (BET) technique. The pore size distributions were obtained according to the BarretJoyner Halenda (BJH) method from the adsorption branch data.

The investigation on thermal stability of the two catalysts was carried out via Mettler Toledo TGA/ SDTA $851^{\mathrm{e}}$ thermo balance using an open alumina crucible of $100 \mu \mathrm{l}$. The TGA temperature was programmed dynamically from ambient to $700^{\circ} \mathrm{C}$ at heating rate of $5^{\circ} \mathrm{C} \mathrm{min}^{-1}$ under nitrogen with flow rate of $50 \mathrm{ml} \mathrm{min} \mathrm{m}^{-1}$. The elemental content of the catalysts was analysed on an Energy-dispersive X-ray (HITACHI S530, Japan).

Attenuated total reflection Fourier transform infra-red (ATR-FTIR) spectra were recorded on a Thermo Scientific Nicolet 6700 FT-IR spectrometer (Waltham, MA, USA) at room temperature with a resolution of $4 \mathrm{~cm}^{-1}$ and a 64-scan signal from 600$4000 \mathrm{~cm}^{-1}$ in absorbance mode.

\section{Catalytic Activity Measurements}

The catalytic activity of HT3.0f and HT3.0c were tested on the transesterification of glycerol with ethylene carbonate using a $250 \mathrm{ml}$ three-necked round-bottom flask. The system was equipped with a stirring bar, a thermometer and a reflux condenser. Eighteen grams of glycerol ( 0.2 mole) and $17.6 \mathrm{~g}$ of ethylene carbonate $(0.2$ mole $)$ together with $2.5 \mathrm{~g}$ of HT3.0f catalyst were charged into the flask. The mixture was heated to $180^{\circ} \mathrm{C}$ under stirring for $5 \mathrm{hr}$. The mixture was then cooled to room temperature. It was filtered off to remove the catalyst. The same procedure was repeated using HT3.0c catalyst.

\section{Product Analysis}

The product mixture compositions were quantitatively analysed on a gas chromatography (HP 6980 Agilent Technologies, US) spectrophotometer equipped with a non-polar HPInnowax capillary column $(30 \mathrm{~m} \times 0.25 \mathrm{~mm} \times 0.25$ $\mu \mathrm{m})$ and a flame ionisation detector. The initial temperature of the column was set at $80^{\circ} \mathrm{C}$ and raised up to $250^{\circ} \mathrm{C}$ with a programming rate of $10^{\circ} \mathrm{C} \mathrm{m^{-1 }}$ for $30 \mathrm{~min}$. The injection and detector temperatures were kept at $250^{\circ} \mathrm{C}$ and $260^{\circ} \mathrm{C}$, respectively with Helium (He) as the carrier 
gas. The method development used as reported by Mariam et al. (2016) where qualitative and quantitative evaluation were identified.

\section{RESULTS AND DISCUSSION}

\section{Catalyst Characterisation}

The structural and chemical properties of the HT3.0f and HT3.0c were analysed via various physico-chemical characterisation techniques. Figure 1 shows the XRD profiles of HT3.0f and HT3.0c. For HT3.0f, the presence of peaks at $12^{\circ}$, $23^{\circ}, 35^{\circ}, 40^{\circ}, 47^{\circ}, 62^{\circ}$ and $63^{\circ}$ confirmed a crystalline patterns characteristic of $\mathrm{Mg} / \mathrm{Al}$ hydrotalcite. These observations were also reported by Cavani et al. (1991).

The characteristic reflections of HT3.0c was clearly observed at $45^{\circ}$ and $65^{\circ}$ which corresponded to a MgO-like phase for all the calcined samples. Based on the 'search and match' technique in XRD database, the prepared HT3.0f and HT3.0c diffractogram matched with the results from the study of Magnesium Aluminum Hydroxide Carbonate Hydrate carried out by Vaccari et al. (1995).

The catalyst has a MgO-like structure, where $\mathrm{Al}^{3+}$ cation dissolved in the lattice to form a solid solution as described by Millange et al. (2000). Studies by Kustrowski et al. (2004), confirmed that all the XRD patterns of the mixed oxides (calcined hydrotalcites) exhibited the typical features of a mixed oxide of an $\mathrm{MgAlO}$ type.
The spectroscopic data of HT3.0f and HT3.0c catalysts were tabulated in Table 1. The N2 adsorption of HT3.0c exhibited type IV isotherm with a hysteresis loop indicating the characteristics of a mesoporous solid (Gubbins et al., 2009). The BET surface area of HT3.0c and HT3.0f catalysts were found to be $179 \mathrm{~m}^{2} \mathrm{~g}^{-1}$ and $81 \mathrm{~m}^{2} \mathrm{~g}^{-1}$, respectively. The pore volume measured for both HT3.0c and HT3.0f catalysts were $0.59 \mathrm{~cm}^{3} \mathrm{~g}^{-1}$ and $0.19 \mathrm{~cm}^{3} \mathrm{~g}^{-1}$, respectively.

Cavani et al. (1991) reported that a bigger surface area and pore volume were obtained upon calcination due to metal migration from the bulk to the surface of the mixed oxides medium. The pore size distributions of the HT3.0f and HT3.0c catalyst gave average pore diameters between 10 and $80 \AA$, respectively as shown in Figure 2.

Based on the thermogram in Figure 3, the thermal behaviour of HT3.0c catalyst was observed. The loss occurred between $25^{\circ} \mathrm{C}$ to $250^{\circ} \mathrm{C}$, could be attributed to water elimination from the interlayer, which gave losses of about $12.5 \%$ in the catalyst. The anionic species present in the HT3.0c catalyst were traces of $\mathrm{CO}_{3}{ }^{2-}$ resulted from adsorption of atmospheric carbon dioxide and decarboxylation at temperature above $250^{\circ} \mathrm{C}$. Above temperature $250^{\circ} \mathrm{C}$, the cation layers $\left(\mathrm{Mg}^{2+}\right.$ and $\left.\mathrm{Al}^{3+}\right)$ started to decompose to carbonate ions, with weight loss of $31.26 \%$. The phase transformation took place at temperature above $420^{\circ} \mathrm{C}$.

The differences in IR transmittance pattern for HT3.0f and HT3.0c catalysts can be observed in Figure 4. Upon calcination of catalyst HT3.0f to HT3.0c, we can clearly observe -OH absorption at

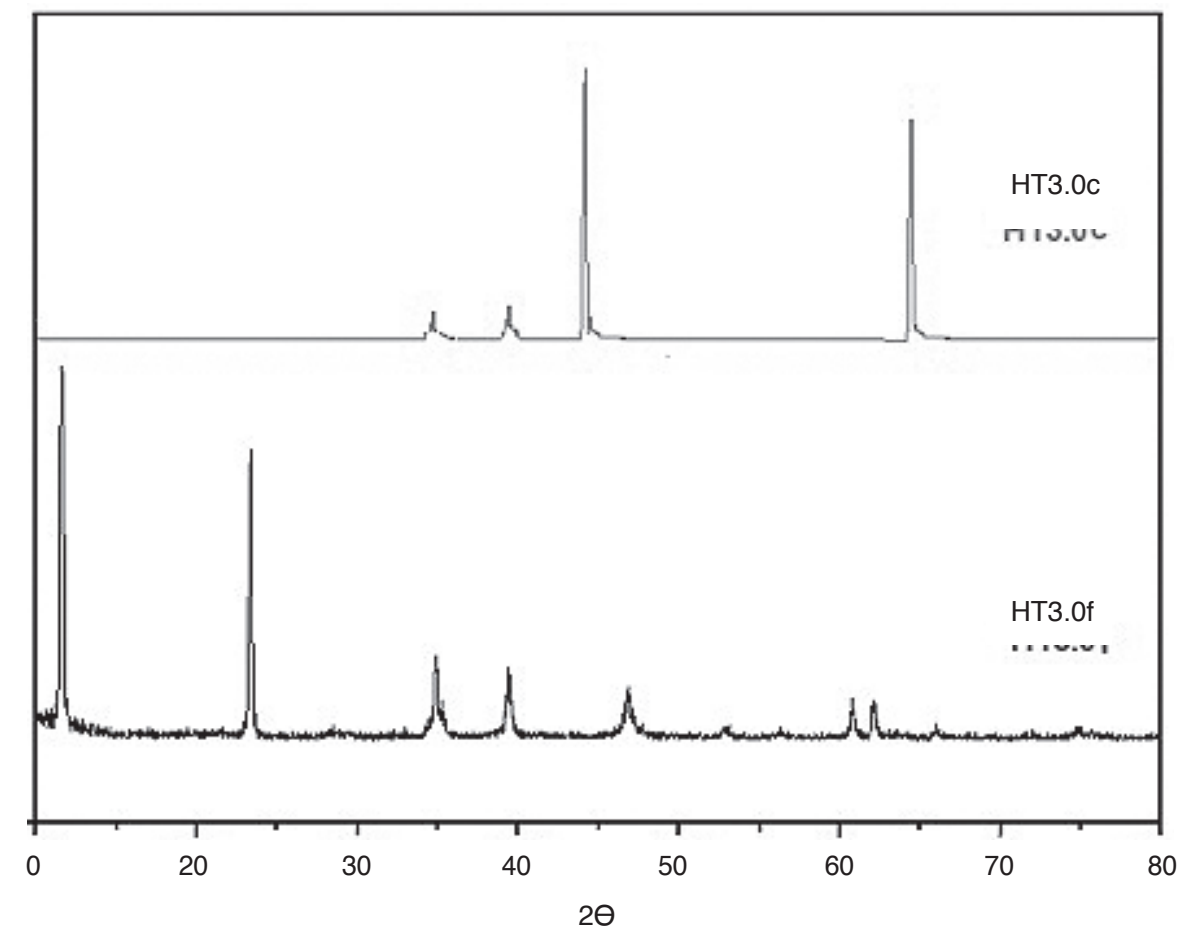

Figure 1. The X-ray diffraction (XRD) pattern of HT3.Of and HT3.0c catalysts. 
TABLE 1. THE BRUNAUER-EMMETT-TELLER (BET) SURFACE AREA AND PORE SIZE DISTRIBUTION OF HT3.0f AND HT3.0c CATALYST

\begin{tabular}{lcccc}
\hline Catalyst & $\begin{array}{c}\text { aSBET } \\
\left(\mathbf{m}^{2} \mathbf{g}^{-1}\right)\end{array}$ & $\begin{array}{c}\text { Pore } \\
\text { volume } \\
\left(\mathbf{c m}^{3} \mathbf{g}^{-1}\right)\end{array}$ & $\begin{array}{c}\text { Pore } \\
\text { diameter } \\
(\mathbf{n m})\end{array}$ & $\begin{array}{c}\text { Atomic } \\
\text { ratio } \\
\mathbf{M g} / \mathbf{A l}\end{array}$ \\
\hline HT3.0f & 81 & 0.19 & 3.81 & $3.04: 1.00$ \\
HT3.0c & 179 & 0.59 & 7.74 & $2.35: 1.00$ \\
\hline
\end{tabular}

Note: asBET-BET surface area.

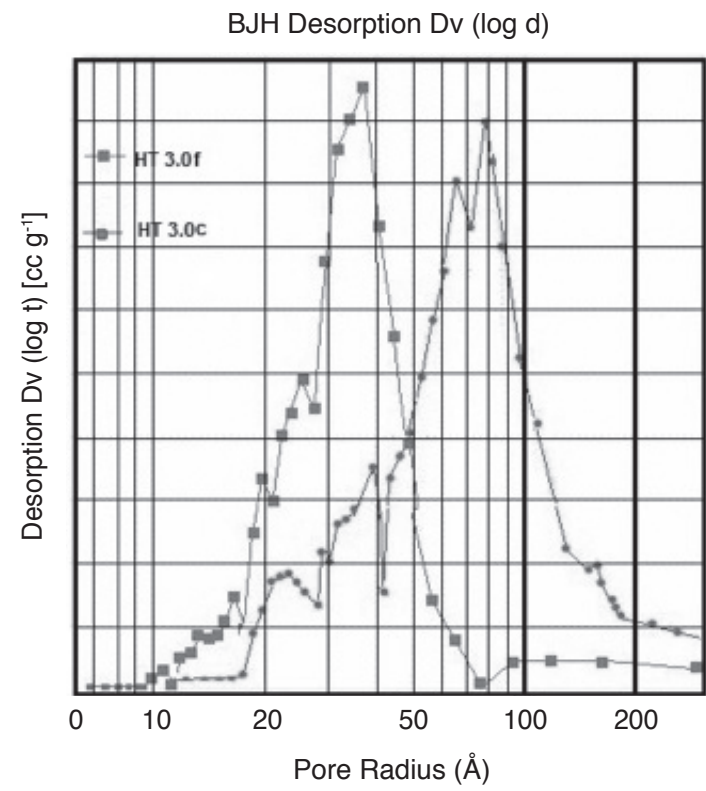

Figure 2. Pore size distribution of the HT3.0f and HT3.0c catalysts from $\mathrm{N}_{2}$ desorption branch using Barrett-Joyner-Halenda (BJH) method.
$3449 \mathrm{~cm}^{-1}$. The vibrations of the interlayer $\mathrm{CO}_{3}^{2-}$ is attributed by the presence of sharp peak at 1370 $\mathrm{cm}^{-1}$. Prior to calcination, synthesised catalyst (HT3.0f) contained traces of $\mathrm{NO}_{3}^{-}$from the peak at $1384 \mathrm{~cm}^{-1}$ (Parida and Das, 2000). This impurity was completely removed after calcination. Again, Parida and Das (2000) reported that the band appearing between 450 and $800 \mathrm{~cm}^{-1}$, represented the characteristics stretching vibration of $\mathrm{Mg}^{2+}-\mathrm{OH}^{-}$ bond in Mg-Al-hydroxy-carbonate.

\section{Catalytic Activity of HT3.0c Catalyst}

The base-catalysed transesterification between ethylene carbonate and glycerol to produce glyceryl carbonate using HT3.0c catalyst is shown in Figure 5.

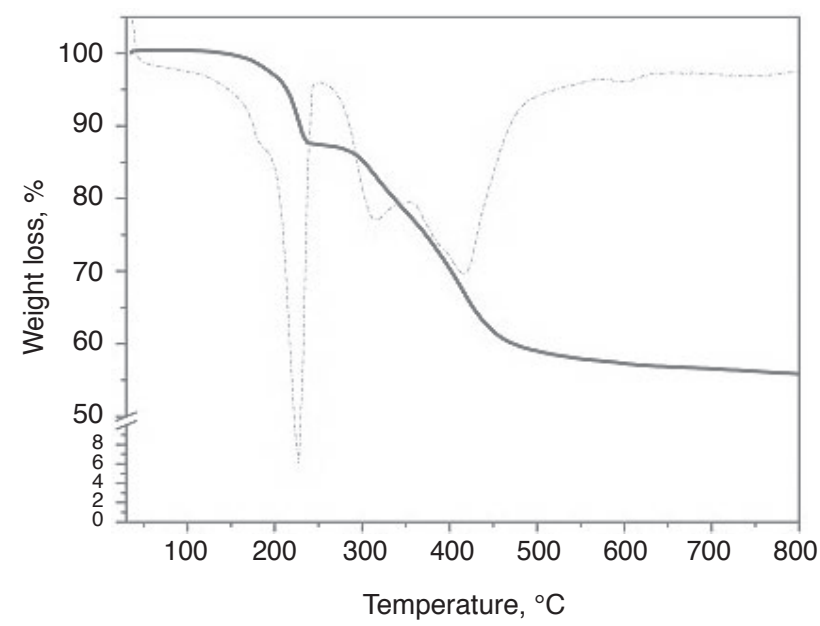

Figure 3. Thermogram spectra of HT3.0c catalyst.

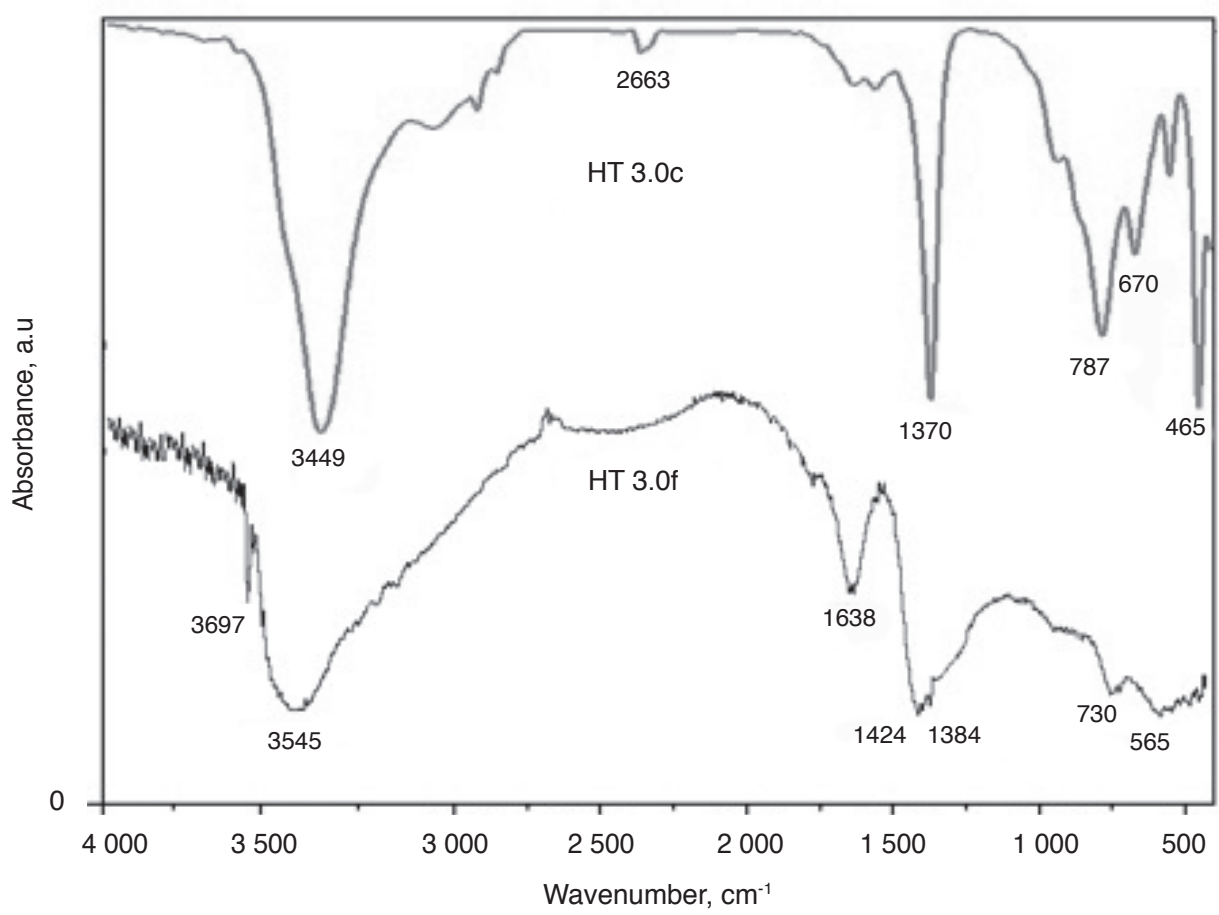

Figure 4. The differences in IR transmittance deformation band for HT3.Of and HT3.0c catalysts. 


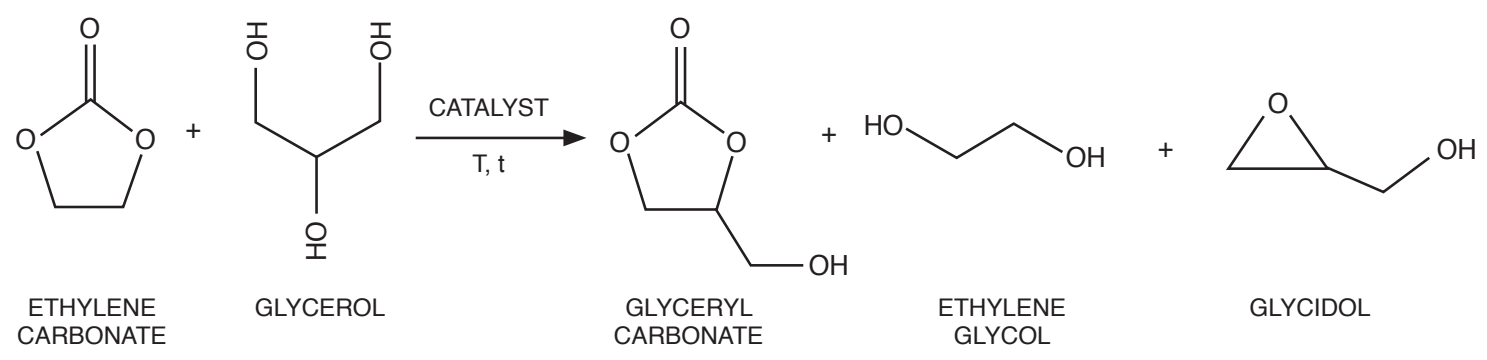

Figure 5. Synthesis of glyceryl carbonate from glycerol and ethylene carbonate.

The percentage composition of the product mixtures obtained after $5 \mathrm{hr}$ of reaction at $80^{\circ} \mathrm{C}$ is shown in Table 2. The reaction without catalyst (Blank) was found to be slow, giving only 6.39\% of GC. Catalyst HT3.0c was found to significantly improve the yield of GC to $71.58 \%$. When using HT3.0f, only $39.35 \%$ of GC was obtained.

\section{TABLE 2. THE PERCENTAGE OF PRODUCTS FROM GAS CHROMATOGRAPHY OF TRANSESTERIFICATION OF GLYCEROL WITH ETHYLENE CARBONATE}

\begin{tabular}{lcccc}
\hline Sample & $\begin{array}{c}\text { Unreacted } \\
\text { glycerol } \\
(\%)\end{array}$ & $\begin{array}{c}\text { Glyceryl } \\
\text { carbonate } \\
(\%)\end{array}$ & $\begin{array}{c}\text { Ethylene } \\
\text { glycol } \\
(\%)\end{array}$ & $\begin{array}{c}\text { Glycidol } \\
\mathbf{( \% )}\end{array}$ \\
\hline $\begin{array}{l}\text { Blank } \\
\text { (no catalyst) }\end{array}$ & 74.91 & 6.39 & 8.06 & 10.64 \\
Catalyst HT3.0f & 41.48 & 39.35 & 11.93 & 7.24 \\
Catalyst HT3.0c & 11.57 & 71.58 & 16.05 & 0.80 \\
\hline
\end{tabular}

Note: Operating condition: temperature, $180^{\circ} \mathrm{C}$; ethylene carbonate, 0.2 mole; glycerol, 0.2 mole; catalyst loading, $7 \%$ by weight of total reactants; reaction duration, $5 \mathrm{hr}$.

\section{Reusability Study of HT3.0c}

The reusability test of $\mathrm{HT} 3.0 \mathrm{c}$ catalyst was assessed for 10 reaction cycles. Based on the XRD diffractogram pattern of reused HT3.0c catalyst for three reaction cycles in Figure 6, revealed that HT3.0c did not change chemically nor it involved in leaching matters as the diffractogram profile was all consistent with the original HT3.0c. The pattern shape was in accordance to the diffractogram of pure hydrotalcite obtained by Cavani et al. (1991).

Reusability is one of the advantages of heterogeneous catalysts over homogeneous catalysts. In this study, reusability of HT3.0c catalyst was investigated by recycling the catalyst from one reaction to another without washing or drying of the catalyst cake obtained via vacuum filtration separation from the reaction mixture. Based on Figure 7, the reusability of HT3.0c catalyst was successfully tested for 10 subsequent cycles, where the conversion and GC compositions obtained for the second and third cycles were close to the first cycle using fresh HT3.0c catalyst. After the eight cycle, conversion was reduced and GC compositions

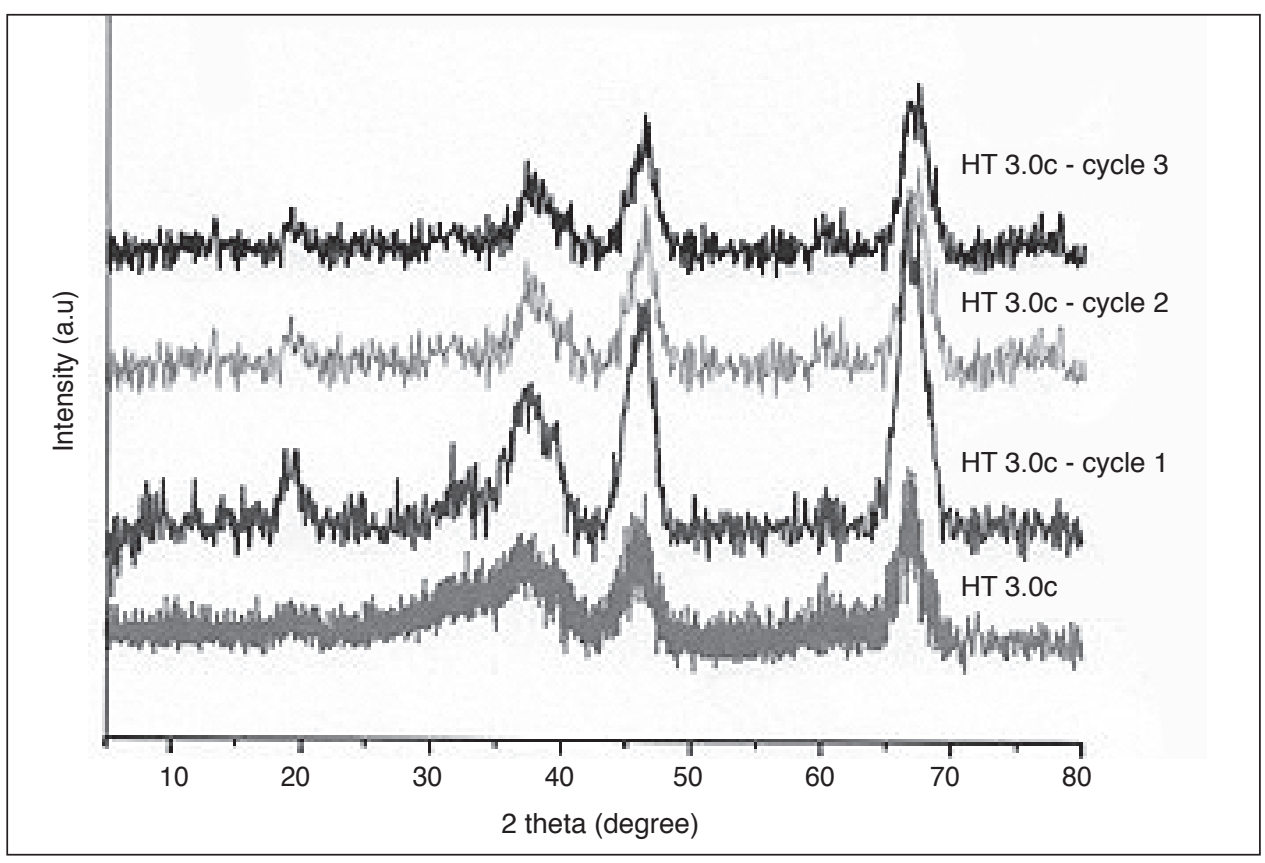

Figure 6. The X-ray diffraction (XRD) analysis for recycle HT3.0c catalyst. 
Reusability Study of HT 3.0c in Transesterification of Glycerol and Ethylene Carbonate

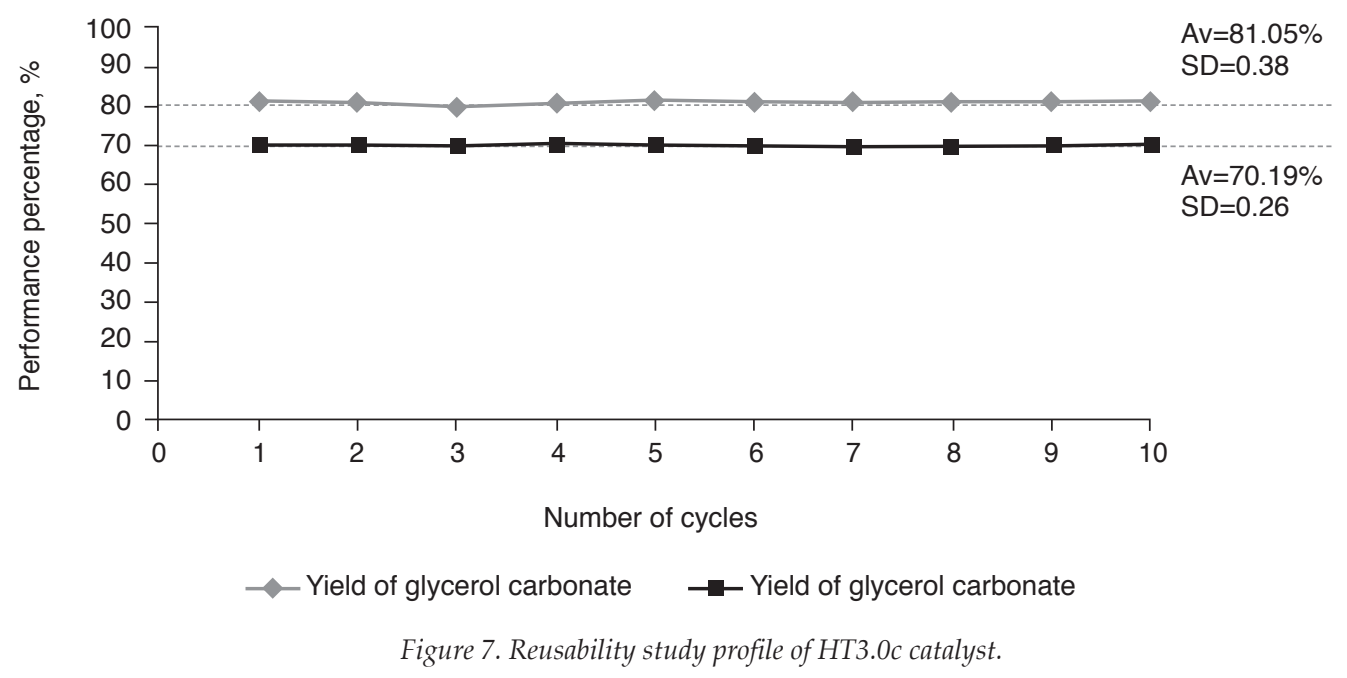

seemed to change dramatically. Hence, HT3.0c catalyst was found to have good stability as a reusable heterogeneous catalyst as its catalytic activity was unchanged for eight subsequent cycles in the production of GC via transesterification of glycerol with ethylene carbonate.

\section{CONCLUSION}

Transesterification of glycerol with ethylene carbonate was successfully carried out by employing HT3.0c catalyst (hydrotalcite) for glyceryl carbonate production. The optimum reaction conditions were established as $180^{\circ} \mathrm{C}, 7 \%$ catalyst, a mole ratio of 1:1 (glycerol:ethylene carbonate) and a duration of $5 \mathrm{hr}$. The uneconomical process, tedious separation technique and issue on safety of the conventional approach using homogeneous catalyst can now be replaced with a more environmental-friendly heterogeneous catalyst and a better separation process. The catalyst was reusable and the conversion of glycerol to GC was reproducible for eight subsequent cycles of reaction.

\section{ACKNOWLEDGEMENT}

The authors would like to thank the Director-General of MPOB for permision to publish this article.

\section{REFERENCES}

ARESTA, M; DIBENEDETTO, A; NOCITO, F and FERRAGINA, C (2009). Valorization of bio-glycerol: new catalytic materials for the synthesis of glycerol carbonate via glycerolysis of urea. J. Catal. Vol. 268: 106-114.
BEHR, A; EILTING, J; IRAWADI, K; LESCHINSKI, $\mathrm{J}$ and LINDNER, F (2008). Improved utilisation of renewable resources: new important derivatives of glycerol. Green Chem. Vol. 10: 13-30.

BELL, J B and ARTHUR, C V (1959). US patent 2, 915, 529 .

CAVANI, F; TRIFIRO, F and VACCARI, A (1991). Hydrotalcite-type anionic clays: preparation, properties and applications. Cat. Today Vol. 11: 173302.

CHOO, Y M; MA, A N; CHAN, K W and YUSOFF, B (2005). Palm diesel: an option for greenhouse gas mitigation in the energy sector. J. Oil Palm Res. Vol. 17: 47-52.

CLIMENT, M J; CORMA, A; FROTOS, P D; IBORRA, S; NOY, M; VELTY, A and CONCEPTION, P (2010). Chemicals from biomass: synthesis of glycerol carbonate by transesterification and carbonylation with urea with hydrotalcite catalysts. The role of acid-base pairs. J. Catal. Vol. 269: 140-149.

CORMA, A; ABD HAMID, S B; IBORRA, S and VELTY, A (2005). Lewis and bronsted basic active sites on solid catalysts and their role in the synthesis of monoglycerides. J. Catal. Vol. 234: 340-347.

FAN, X; RACHEL, B and YONG, CZ (2010). Glycerol (by-product of biodiesel production) as a source for fuels and chemicals - mini review. The Open Fuels $\mathcal{E}$ Energy Sci. J. Vol. 3: 17-22.

GUBBINS, K E and KARGER, J (2009). Hysteresis Phenomena in Mesoporous Materials. Dissertation, NC State University, USA. 
KUSTROWSKI, P; CHMIELARZ, L; BOZEK, E; SAWALHA, M and ROESSNER, F (2004). Acidity and basicity of hydrotalcite derived mixed $\mathrm{Mg}-\mathrm{Al}$ oxides studied by test reaction of $\mathrm{MBOH}$ conversion and temperature programmed desorption of $\mathrm{NH}_{3}$ and $\mathrm{CO}_{2}$. Mater. Res. Bull. Vol. 39: 263-281.

MILLANGE, F; WALTON, R I and O'HARE, D (2000). Time-resolved in situ X-ray diffraction study of the liquid-phase reconstruction of $\mathrm{Mg}-$ Al-carbonate hydrotalcite-like compounds. J. Mat. Chem. Vol. 10: 1713-1720.

MOULOUNGUI, Z; YOO, J W; GACHEN, C A and GASET, A (1996). EUR patent 0, 739, 888.

MURASE, A (1987). JP patent 6, 222, 709.

PARIDA, K and DAS, J (2000). Mg/ Al hydrotalcite: preparation, characteristic and ketonisation of acetic acid. J. Mol. Catal. A: Chem. Vol. 151: 185-192.

NIK SITI MARIAM, N M D; ZAINAB, I; HOONG, S S; YEONG, S K and HAZIMAH, A H (2016). Sythesis of glyceryl carbonate via microwave. J. Oil Palm Res. Vol. 28 (1): 131-141.

PRATI, L; SPONTONI, P and GAIASSI, A (2009). From renewable to fine chemicals through selective oxidation: the case of glycerol. Top. Catal. Vol. 52: 288-296

RUPPERT, A M; MEELDIJK, J D; KUIPERS, B W M; ERNE, B H and WECKHUYSEN, B M (2008). Glycerol etherification over highly active CaO- based materials: new mechanistic aspects and related colloidal particle formation. Chem. A Eur. J. Vol. 14: 2016-2024.

SHIEH, W C; DELL, $S$ and REPIC, O (2002). Nucleophilic catalysis with 1,8-diazabicyclo undec7ene (DBU) for the esterification of carboxylic acids with dimethyl carbonate. J. Org. Chem. Vol. 67: 21882191.

SONNATI, $\mathrm{M}$ O; AMIGONI, S; TAFFIN DE GIVENCHY, E P; DARMANIN, T; CHOULET, O and GUITTARD, F (2013). Glycerol carbonate as a versatile building block for tomorrow: synthesis, reactivity, properties and applications. J. Green Chem. Vol. 15: 283-306.

SUGITA, A; SONE, Y and KAERYAMA, M (1994). JP. patent 06, 329, 663.

VACCARI, A; GAZZANO, I N; PONCELET, G; MARTENS, J; DELMON, B; JACOBS, $\mathrm{P}$ A and GRANGE, P (1995). Preparation of Catalysts VI. Studies in Surface Science and Catalysis. Vol. 91. Elsevier. p. 309.

VIEVILLE, C; YOO, J W; PELETS, $S$ and MOULOUNGUI, Z (1998). Synthesis of glycerol carbonate by direct carbonatation of glycerol in supercritical $\mathrm{CO}_{2}$ in the presence of zeolites and ions exchange resins. Cat. Lett. Vol. 56: 245-247.

YOO, J; MOULOUNGUI, Z and GASET, A (2001). US patent $6,316,641$. 